\title{
Research on Productization Design of Candied Fruit Packaging Based on Sustainable Concept
}

\author{
Siqi Guo ${ }^{1, *}$ Xiaoci Pei ${ }^{1}$ \\ ${ }^{1}$ Product Design Department, School for Creative Studies, Quanzhou Institute of Information Engineering, \\ Quanzhou, Fujian, China \\ *Corresponding author. Email: guosiqi59@163.com
}

\begin{abstract}
The purpose is to extend the service life of candied packaging, maximize the value of food packaging, optimize the product using experience, and use the power of design to help environmental protection and sustainable development. The method is to summarize the problems of existing candied fruit packaging in the market, combined with sustainable design concepts, design and study the productization of candied fruit packaging. Taking the mature production technology of polyethylene, polypropylene, and polylactic acid as examples, this paper discussed the design principles from the four aspects of practicability, rationality, commercialization, and innovation in details which designers and developers should follow, and the design methods of confection packaging productization are explored in conjunction with actual cases. Conclusion: The candied packaging productization can maximize the value of materials, enrich packaging functions, and provide consumers with multi-level user experience. It is an innovative design method to enhance the added value of food packaging design, save resources, and promote low-carbon life. It is of positive significance to enhance the brand image of candied fruit, the extension of the upstream and downstream industrial chain.
\end{abstract}

Keywords: Candied fruit packaging, Packaging productization, Sustainable design.

\section{INTRODUCTION}

As a popular snack food, the candied fruit has a stable market share for many years. In the eastern coastal areas of China, almost every province has its own well-known candied foods and brands in its region, and its sales volume and output value are very impressive. Affected by traditional mindset, market environment and Chinese eating habits, most of the candied fruit packaging is directly discarded after the food package was opened, and the function is only to temporarily wrap the food; according to the statistics of China Packaging Industry Association, $70 \%$ of product packaging in China is discarded after the first use, it generates more than 16 million tons of waste each year and increases year by year. It is clearly stated in the "Law of the People's Republic of China on the Prevention and Control of Solid Waste Pollution and Environment" as amended on November 7, 2016: Advocating production methods and living conditions that are beneficial to environmental protection ways to encourage units and individuals to purchase and use recycled products and reusable products. [1] This article combines the concept of sustainable design to carry out design research on the problem of low utilization rate of candied packaging, and explores the product design method of food packaging.

\section{RESEARCH OVERVIEW}

Sustainable design is a new attempt of the design community to base itself on the development of people and nature, and people and society. From green design, ecological design to sustainable design, product design in the product development process is not limited to the appearance of the product, but is required to the product design stage takes into account the product cost, material, appearance, pain points, functions, impact on the environment, and product quality. [2] The packaging of candied products was usually neglected during designing. Many companies focus on the pattern design of candied packaging and the costs of materials, ignoring the systematic and 
integral nature of products packaging, resulting in the disconnection and isolation of packaging and products.

This topic is based on Fujian, and takes Zhangzhou candied fruit industry as an entry point to carry out research and explore the sustainable design method of productization design of food packaging. Zhangzhou sweetmeat is one of the representatives of Fujian-style candied fruit, an important part of the food industry and one of the main forces of Zhangzhou's food economy. Zhangzhou, as one of the largest food packaging production bases in China, has 28 food packaging container related enterprises, with an annual output value of more than 5 billion yuan. The output accounts for about $80 \%$ of Fujian Province, it is representative to take Zhangzhou food packaging industry as a research sample.

\section{EXISTING CANDIED FRUIT PACKAGING FEATURES}

Taking the major supermarkets, brand stores, and e-commerce channels as examples, the packaging of commercially available candied products can be roughly divided into five categories: plastic sealed bags, sealed bags, PP/ PE plastic cans, carton paper bags, and other metal packaging (such as aluminum, iron and other packaging materials). ("Figure 1")

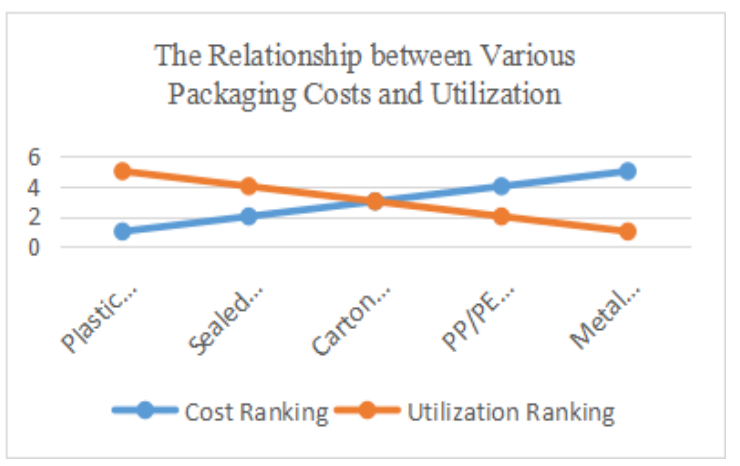

Figure 1 Relationship between various types of packaging costs and utilization rate.

Sorted by the author

b The larger the value, the higher the cost of such packaging and the lower the utilization rate

From the perspective of cost and utilization rate, the cost of plastic sealed bags is the lowest, but the utilization rate is also the lowest. Generally, it is discarded after unpacking or after the candied fruit is eaten. The second is the sealed bag. This type of packaging takes into account the problem that consumers can not eat them all at once. It is convenient to design a re-sealable sealing strip, and can be reused as a storage bag for a small amount of items. But when reusing it, people needs to wash and dry the packaging, few consumers do this because the procedure is too cumbersome. The third is carton paper bags, this kind of packaging has improved visual and texture, but the cost is slightly higher than plastic bags, some hard paper outer packaging can be reserved for other uses; the fourth is PP / PE canned, this kind of packaging cost is relatively high, but the utilization rate has also increased. After the candied fruit is eaten, many consumers are willing to use it as a storage tank due to the characteristics of PP / PE material that is wear-resistant and easy to store. Metal boxes and cans with the highest relative cost and the highest utilization rate are generally used by consumers as objects such as storage jars or flower pots, but such packaging often raises the price of the product.

It is easy to see from the graph that the relationship between the cost and the utilization rate organized by the author. Overall, the cost and utilization rate of the carton paper bags are moderate, which is a relatively environmentally friendly packaging form at the present stage. So, will the future preserved packaging design continue this trend, is there a better solution? The following will be analyzed through cases.

\section{PRODUCT DESIGN PRINCIPLES OF CANDIED FRUIT PACKAGING}

"Productization of candied fruit packaging", as the name implies, refers to the inclusion of food packaging in the category of "product design", from the original pattern design and material selection advanced to the level of design the "product"; extend the packaging life cycle, make better use of the characteristics of materials and play the role of packaging, and integrate sustainable design concepts into packaging design.

\subsection{The Principle of Practicability}

The principle of practicability is the functional prerequisite for the commercialization of food packaging. Pizza Hut (Taiwan) launched a pizza take-out box in 2015, which can be turned into a projector through simple operations. It is really a pleasant thing you can watch a movie while eating pizza. The design of "projector pizza box" based on the consumer's real using situation, with practical functions, moderate costs, easy to implementate, 
and better follows the practical principles of food packaging design. ("Figure 2")

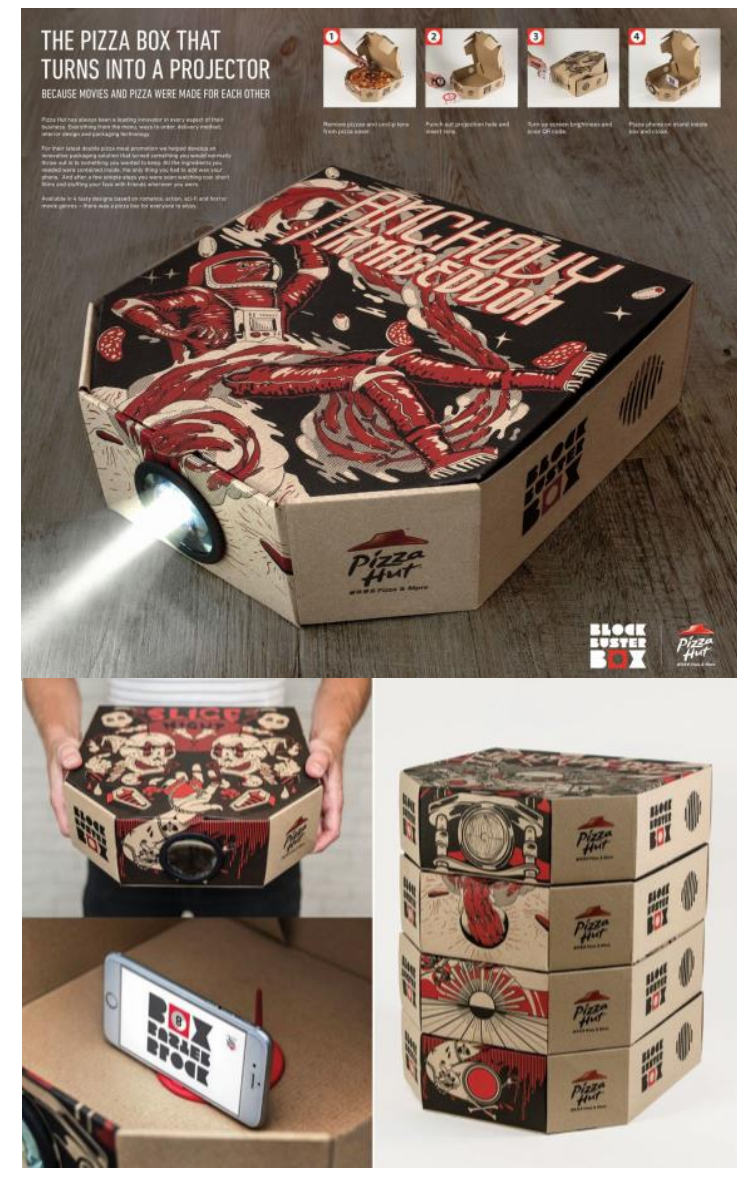

Figure 2 Pizza hut packaging — which can be used as a projector.

a Source: www.brain.com.tw

Due to the low cost of candied fruit itself, generally in common commercially available sweetmeat products, the packaging way is directly contact or directly wrapped with candied fruit. [3] Thicker kraft paper, polyethylene film or polypropylene film is often selected for printing convenience. At present, the kraft paper recycling mechanism is not perfect, polyethylene, polypropylene plastics are difficult to degrade and recycle, which is probably cause the waste of materials and environmental pollution. In addition to wrapping food, designing a relatively practical function for sweetmeat packaging can extend its service life and better give full play to the value of packaging; therefore, the two key directions for the practical design of candied fruit packaging are to increase the utilization rate of materials and increase the practical function of packaging.

\subsection{The Principle of Reasonableness}

The principle of rationality is put forward on the basis of the principle of practicability. Designing functional packaging to enhance the added value of packaging is not simply adding various functions to the packaging and designing to enrich the function; it is contrary to the will of consumers and simple complicating the problem is undesirable.

The tea packaging of "Yan Chuan Tea" designed with two materials: wood plate and tinplate, which has an increased difference from the existing packaging, which makes people shine. However, the use of wooden boards to fix tinplate boxes caused a certain waste of space. The tinplate box itself has been able to better ensure that the tea is dry and free from moisture. The use of wood plates in packaging design is far-fetched and lacks rationality. [4] It is an example that violates the principle of rationality. ("Figure 3")

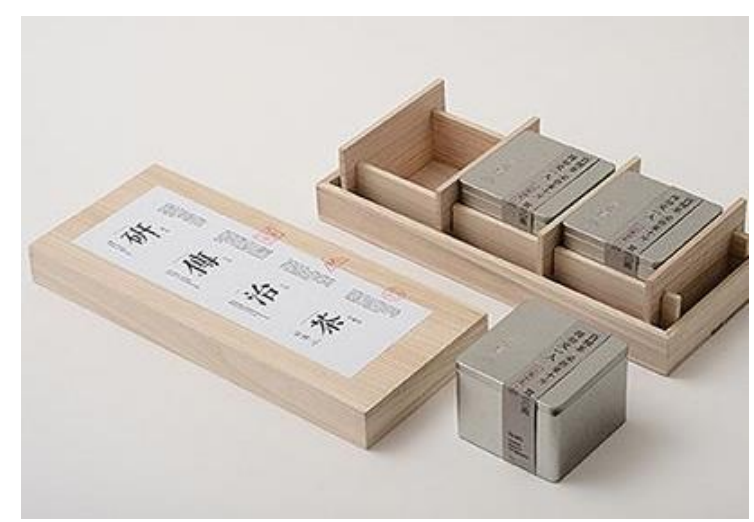

Figure 3 Yan Chuan Tea industry packaging design (Taiwan, China).

Source:www.pinterest.com

On the contrary, the pistachio packaging of the 2014 Red Dot Award works considered the selection of product packaging, the convenience of food eating, packaging recycling and packaging reuse at the beginning of the design, which is reasonable and green. The overall shape of the packaging simulates the appearance of pistachios, and the unpacking and closing methods are similar to the pistachio peeling method; the kraft paper box containing pistachios in the packaging itself can be used as a container, allowing the whole process of "unpack-eat-share-clean up" has become very easy and interesting, and has been maximized the value of the material. ("Figure 4") 


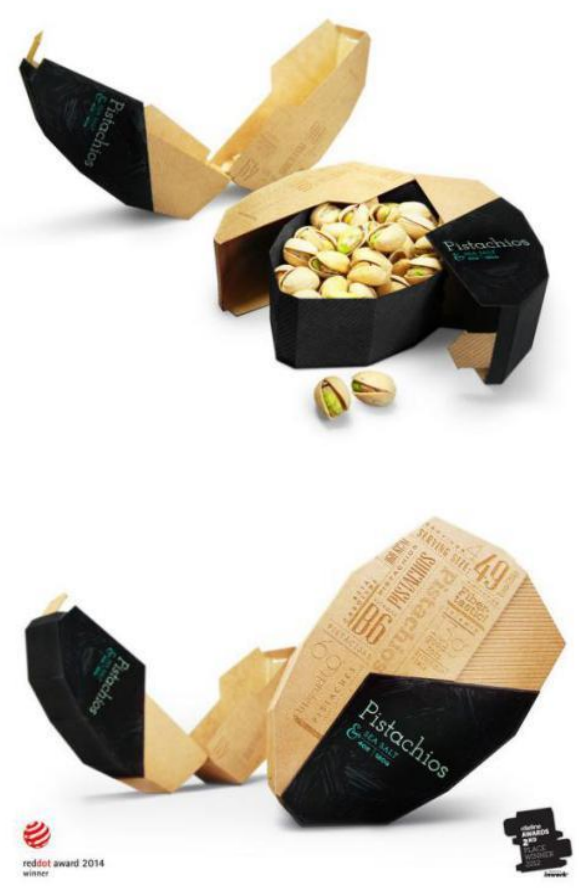

Figure 4 Pistachio packaging design.

\subsection{The Principle of Commercialization}

The principle of commercialization seems to be put forward from the perspective of the manufacturer, but it is actually beneficial to consumers, developers, material suppliers and the environment. The principle of commercialization based on profit, and on the premise of saving materials and controlling product packaging costs try to satisfy consumers' preferences as much as possible. In the product design of candied packaging, follow the principle of commercialization, refuse to create gimmicks, misuse materials, and add exaggerated functions, which can achieve a better balance between environmental protection, material supply, product function and sales popularity. [5]

The Nhà (Vietnam) candied fruit packaging design combines carton packaging and glass bottle packaging. ("Figure 5") The beautiful pattern and sweet candied fruit create a spiritual enjoyment for consumers. The glass bottle has a good sealing property and can be reserved for storage. The carton shell reduces the damage rate of the glass bottle during transportation. With good reusability, it can also be used as a small item storage box after opening. When it is used as a storage box, the packaging surface pattern can help consumers remember the brands and products, it has a certain advertising effect, which is a packaging design case that better follows the principle of product commercialization. [6]

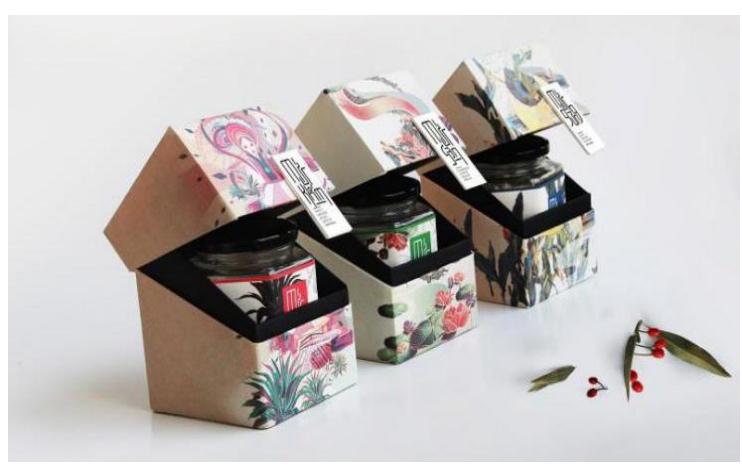

Figure 5 Nhà candied fruit packaging design (Vietnam).

Source: www.pinterest.com

\subsection{The Principle of Innovation}

The productization design of candied fruit packaging, in addition to meeting the practical, reasonable and commercial needs, should also open the gap with existing products and focus on innovation. Although for quite a long time, the packaging of candied fruit is mainly made of polypropylene and polyethylene, which is indeed the most economical and direct form of sweetmeat packaging. However, as a designer, one should be more responsible and accountable, serve consumers with a sustainable perspective, and treat the earth's resources with a development perspective.

Taking the winning works of the packaging group of the Red Dot Design Award 2016 as an example: Have you ever noticed it is inconvenient to take out the potato chips from the barrel? The designer combined the folding structure with the aluminum foil closing, design this "convenient to take" barrel potato chips package. It can be packaging and also be the dishes, which is far more different from the existing products, make an impression. ("Figure 6") 


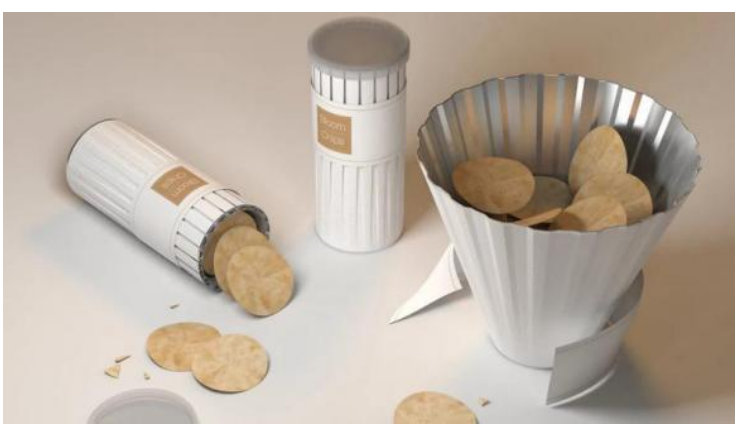

Figure 6 Packing of potato chips in barrels.

Source:www.red-dot.org

New forms, new structures, and new materials are all ways for innovative packaging design. Only to break free from the constraints of existing forms, keep explore and try, we can design food packaging that is more suitable for sustainable development, and it is important for improving the environment and optimizing the industrial structure. [7]

\section{RESEARCH ON \\ PRODUCTIZATION DESIGN METHOD OF CANDIED FRUIT PACKAGING}

Productization design of sweetmeat packaging, that is, to take candied food packaging as an integral part of the target product. Designers need to link product packaging with the physical characteristics of the product itself (such as volume, quality, dryness, gap between particles, etc.), brand philosophy, target users, usage scenarios, etc., so that product packaging and products become integrated, connotation, increase interaction and resonance with consumers, thereby maintaining the heat of the product, ensuring product sales, and increasing brand dependence.

The author designed a set of sustainable use packaging for Zhangzhou preserves. This work won the bronze award in the packaging group of the 4th Cross-strait (Zhangzhou) Industrial Design Innovation Competition in 2019; its main highlight is the adoption of different bottle cap and bottom cap modules matching, so that the candied fruit packaging will present more than 7 different functions, extend the life cycle of the candied fruit packaging, and play the residual value of the material. ("Figure 7")

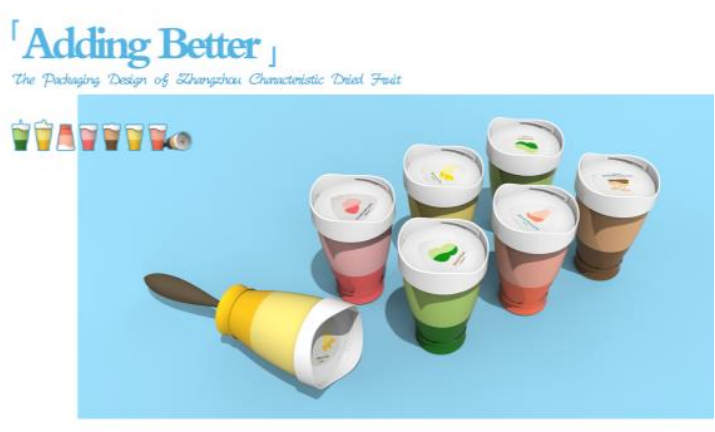

Figure 7 "Tianjia" — the specialty dried fruit packaging design for Zhangzhou.

Designed by the author

\subsection{Increasing Packaging Interactivity}

In addition to bright colors and rich patterns, packaging can also be fun and fun. The "Tianjia" package is divided into two parts, the inside is a layer of polyethylene film, and the outside is a cup body that is injection molded from corn plastic ${ }^{1}$. Under each label sticker on the top, "hidden mystery": remove the sticker and flip the top cover ("Figure 8"), you can randomly achieve a variety of "hidden functions" such as oil bottles, sauce bottles, and piggy banks ("Figure 9"); consumers can also experience the fun of a lucky bag while tasting preserves.

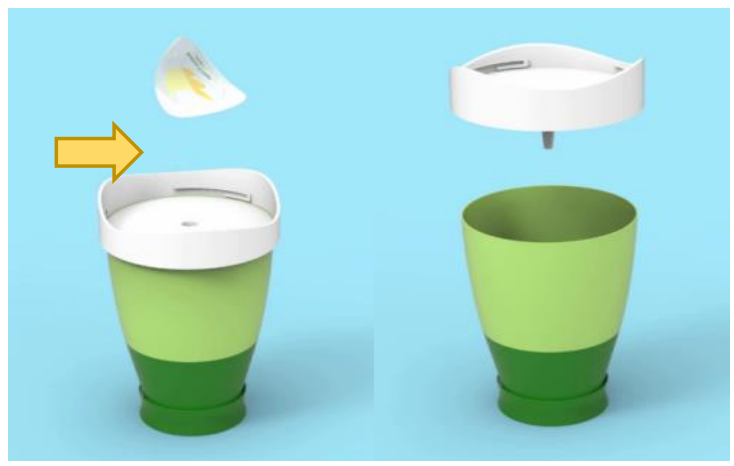

Figure 8 Schematic diagram of the use of "Tianjia" top cover.

a The author painted

1. Corn plastic, scientific name "polylactide" (Polylactide), is a polymer compound obtained by processing corn and other starch-rich crops as raw materials after a series of biochemical techniques. In addition to the same physical properties as chemical plastics, corn plastic is non-toxic and pollution-free. It is a pure biomass plastic that can be widely used in packaging, medical, textile and other fields. 

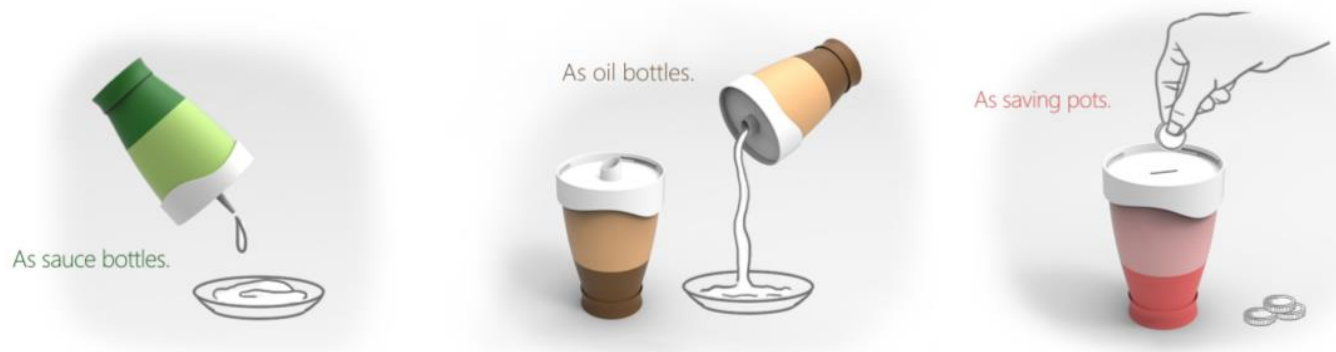

Figure 9 "Tianjia" packaging used as a sauce bottle, oil bottle and piggy bank schematic diagram.

In addition, when two packaging monomers combined together with a certain amount of sand or rice, they can be used as a dumbbell ("Figure 10"). If the top cover is removed, it can also be used as a flower pot or pen holder. ("Figure 11") The subsequent use of packaging can add fun to consumers' lives.

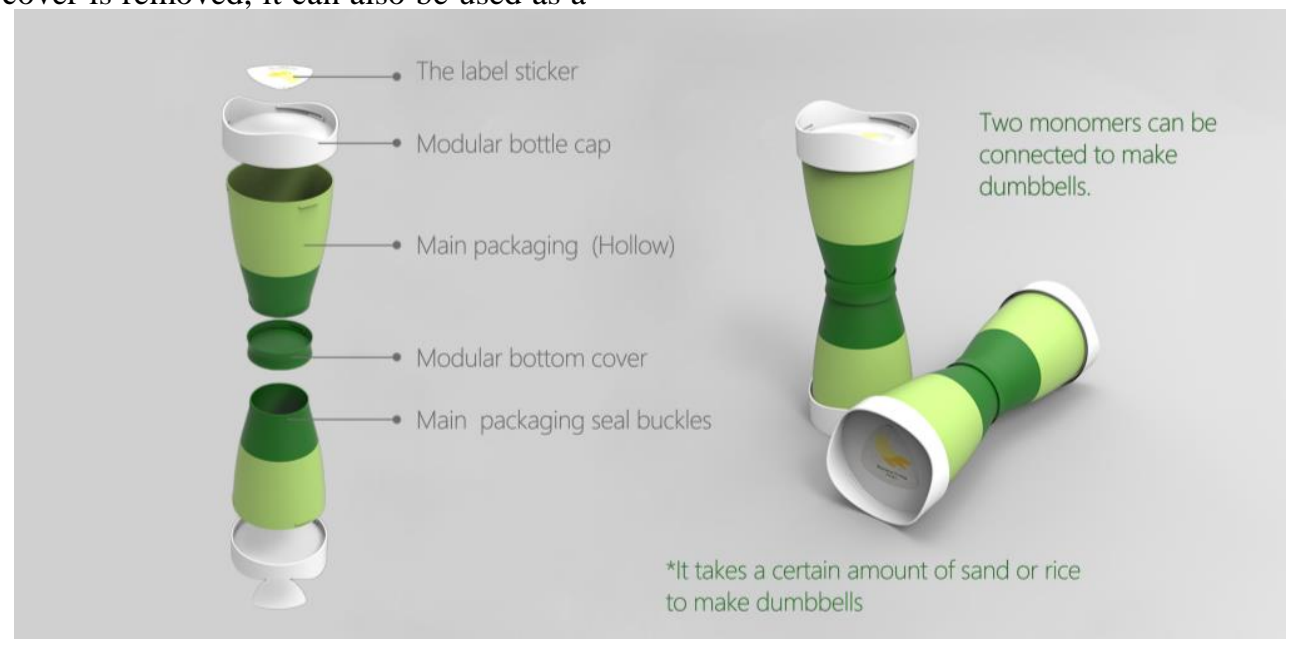

Figure 10 "TianJia" packaging explosion diagram and dumbbell schematic diagram.

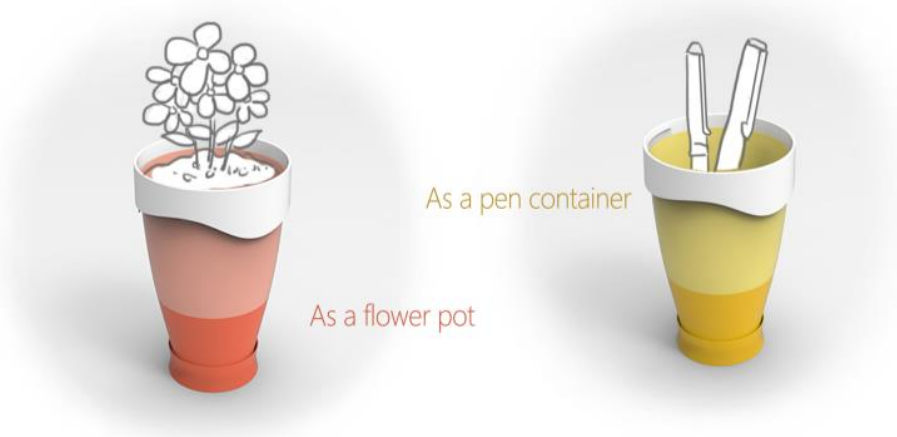

Figure $11 \quad$ "Tianjia" packaging used as flower pots and pen holders. 


\subsection{Integration of Candied Fruit Packaging}

At the beginning of the "Tianjia" packaging design, considering that Zhangzhou is famous for its fruits in China, there are many types of candied fruit, packaging design can use different colors to represent different kinds of dried fruit, and then combine the same modeling elements for family design. The unified cup body, with different top and bottom covers, can achieve multiple functions. Each function seems irrelevant, but through module replacement, each function form is a member of the "Tianjia" series packaging. The integrated design of candied packaging regards packaging as an element of product design at the same level as "shape", "function" and "process", and comprehensively considers three aspects of packaging material selection, function setting, and rationality of material and function matching, making for achieving the effect of "the whole is greater than the sum of the parts". ("Figure 12")

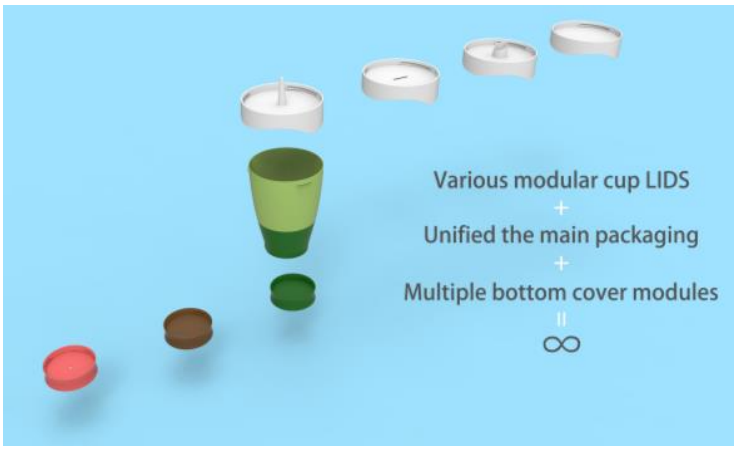

Figure 12 Various modules of "Tianjia" packaging.

\subsection{Connotation of Candied Fruit Packaging}

The connotation of packaging design is put forward on the basis of integration, which can make the packaging and products closely connected to each other.

The shape of the "Tianjia" packaging evolved from the petals of the daffodil flower in Zhangzhou City. The sticker in the middle of the top cover is just like the flower core of the daffodil. ("Figure 13") It is intended to remind consumers that this is a product from Zhangzhou, please pay attention to the food industry in Zhangzhou". Although it is obscure, combined with publicity, such as printing a QR code on the packaging, take advantage of
WeChat or other platforms, consumers who pick up their mobile phone to scan, can look into the story behind this product and its packaging design deeply.

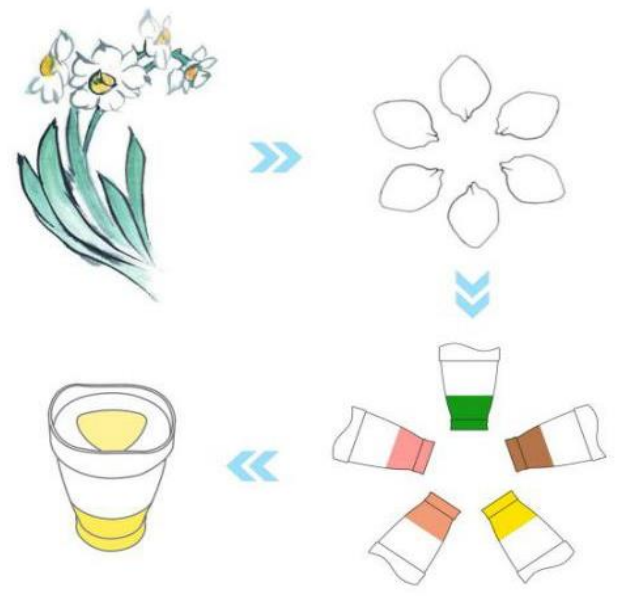

Figure 13 "Tianjia" packaging inspiration source.

The author painted

Connotation of packaging design is an important issue facing current food packaging design. Combined with the cultural background of the place of origin, "told" the story of the product is vividly and interestingly, which has a certain positive significance for enhancing the brand image and increasing the popularity of the product.

\section{CONCLUSION}

Combining sustainable design concepts for productization design of candied fruit packaging, following the principles of practicability, rationality, commercialization, and innovation, starting from increasing the level of packaging interaction, in addition to creating a good purchasing experience, optimizing the using experience, and enhancing buyer's inner satisfaction, it also makes the product and the brand leave a good impression in consumers' hearts, greatly increasing the possibility of buying the brand's products again; taking product packaging as an integral part of the product, taking a holistic view of the "product packaging" and "product function" issues, and make a serialized and modular design to help achieve a better effect of "the overall is greater than the sum of the parts"; The spread of customs will enable products, developers, consumers, and the environment to enter a virtuous circle and develop in a sustainable and scientific manner. 


\section{AUTHORS' CONTRIBUTIONS}

Siqi Guo analysed data and wrote the manuscript, and Xiaoci Pei contributed to revising and editing.

\section{REFERENCES}

[1] Zhang Li, Li Ping. Packaging Science [M]. Beijing: Tsinghua University Press, 2015.

[2] Anne Cheek, Paul Mickleswirt. Sustainable design changes how designers and designers promote sustainability [M]. Changsha: Hunan University Press, 2012.10.

[3] Xin Benchun, Bi Hualin. Corn Plastics - The Fourth Kind of New Chemical Materials. Chemistry Education, 2007, 28 (8): 4-5.

[4] Reimann, M., Zaichkowsky, J., Neuhaus, C., Bender, T. and Weber, B. (2010), Aesthetic package design: A behavioral, neural, and psychological investigation. Journal of Consumer Psychology, 20: 431-441. doi:10.1016/j.jcps.2010.06.009

[5] Rezaei, J., Papakonstantinou, A., Tavasszy, L., Pesch, U., \& Kana, A. (2018). Sustainable product-package design in a food supply chain: A multi-criteria life cycle approach. Packaging Technology and Science, 32(2), 85-101. doi:10.1002/pts. 2418

[6] Steenis, N. D., van der Lans, I. A., van Herpen, E., \& van Trijp, H. C. M. (2018). Effects of sustainable design strategies on consumer preferences for redesigned packaging. Journal of Cleaner Production, 205, 854-865. doi:10.1016/j.jclepro.2018.09.137

[7] Steenis, N. D., van Herpen, E., van der Lans, I. A., Ligthart, T. N., \& van Trijp, H. C. M. (2017). Consumer response to packaging design: The role of packaging materials and graphics in sustainability perceptions and product evaluations. Journal of Cleaner Production, 162, 286-298. doi:10.1016/j.jclepro.2017.06.036. 